\title{
Reuna
}

\section{ESTUDO BIBLIOMÉTRICO SOBRE A PESQUISA CIENTÍFICA DE CAFÉS CERTIFICADOS NA WEB OF SCIENCE}

\section{BIBLIOMETRIC STUDY OF SCIENTIFIC RESEARCH ABOUT COFFEE CERTIFICATION IN THE WEB OF SCIENCE}

\author{
http://dx.doi.org/10.21714/2179-8834/2020v25n2p1-19
}

\author{
Lilian Cervo Cabrera \\ Universidade Estadual de Londrina (UEL), Brasil. \\ E-mail: liliancabrera 86@yahoo.com.br \\ Carlos Eduardo Caldarelli \\ Universidade Estadual de Londrina (UEL), Brasil. \\ E-mail: caldarelli@uel.br
}

Submissão: 2 Ago. 2019. Publicação: 30 Jun. 2020. Sistema de avaliação: Double blind review. Centro Universitário UNA, Belo Horizonte - MG, Brasil. Editor geral: Prof. Dr. Thiago Soares Nunes

Este artigo encontra-se disponível nos seguintes endereços eletrônicos:

http://revistas.una.br/index.php/reuna/article/view/1078

http://dx.doi.org/10.21714/2179-8834/2020v25n2p1-19

\section{Resumo}

Com destaque no mercado internacional, os chamados cafés especiais vêm ganhando espaço e o seu consumo no contexto mundial apresenta tendência crescente. Nesse sentido, o processo de certificação funciona como atestado de qualidade desse tipo de café e assegura sua origem e rastreabilidade aos consumidores. Para os cafeicultores é uma oportunidade de diferenciar seu produto, com vistas a maior rentabilidade e competitividade. Posto isso, o objetivo deste trabalho é analisar, por meio de um estudo bibliométrico, a produção científica quanto ao tema certificação do café na base Web of Science. Foram consideradas as publicações dos últimos 10 anos (2009 a 2019) e essas analisadas por meio do software VOSviewer. Os resultados apontam que estudos sobre fatores socioeconômicos na certificação do café ainda são poucos, sobretudo no aspecto econômico. As temáticas que prevalecem são as relacionadas à saúde e aos aspectos químicos. Nas publicações sobre certificação do café, "comércio justo", "México", "biodiversidade", "qualidade" e "governança" são os termos que mais aparecem nos estudos. Os países que mais publicam sobre o assunto são Estados Unidos, Brasil e Alemanha, no entanto, desde 2016, países da Ásia e da África têm se destacado.

Palavras-chave: Cafeicultura; Certificação; Cafés especiais; Bibliometria.

\section{Abstract}

With special attention in the international market, the so-called special coffees have been gaining space and their consumption in the world context presents an increasing tendency. In this sense, the certification process serves as a quality certification for this type of coffee and ensures its origin and traceability to consumers. For coffee 
growers is an opportunity to differentiate their product, with a view to greater profitability and competitiveness. Thus, the objective of this work is to analyze, through a bibliometric study, the scientific production regarding the topic of coffee certification in the Web of Science database. We considered the publications of the last 10 years (2009 to 2019) and the results analyzed through VOSviewer software. The results indicate that studies on socioeconomic factors in coffee certification are still few, especially in the economic aspect. The themes that prevail are those related to health and chemical aspects. In the publications on coffee certification, "fair trade", "Mexico", "biodiversity", "quality" and "governance" are the terms that most appear in the studies. The countries that publish most on the subject are the United States, Brazil and Germany, however, since 2016, countries in Asia and Africa have stood out.

Keywords: Coffee; Certification; Specialty coffees; Bibliometry.

\section{Introdução}

O café é uma importante commodity na economia mundial. Trata-se de um dos mais valiosos produtos primários comercializados no mundo. Mesmo ainda considerado uma commodity, o café vem ganhando status de produto especial no mercado internacional, em razão das exigências cada vez maiores dos consumidores (SINDICATO DA INDÚSTRIA DE CAFÉ DO ESTADO DE MINAS GERAIS, 2005). Nas últimas décadas, a crescente importância do varejo e a demanda de cafés especiais no mundo todo impactaram o comércio mundial do grão. Segundo a Empresa Brasileira de Pesquisa Agropecuária (EMBRAPA, 2018), o consumo mundial de cafés especiais cresceu seis vezes mais que o tradicional nos últimos 15 anos e expandiuse não apenas em mercados tradicionais, como os Estados Unidos, a Alemanha e a França, mas também em mercados orientados para o chá, como o Japão, a Coréia do Sul e a China.

Se esse ritmo de crescimento continuar, o setor cafeeiro precisará de 300 milhões de sacas de café até 2050, o que significa duplicar ou até triplicar a atual produção mundial anual (KILLEEN; HARPER, 2016; WORLD COFFEE RESEARCH, 2017). No ano-safra de $2017 / 18$, os cafeicultores produziram uma safra mundial recorde de quase 162 milhões de sacas de $60 \mathrm{~kg}$. Arábica e robusta são as duas principais espécies de café cultivadas no mundo (INTERNATIONAL COFFEE ORGANIZATION - ICO, 2019).

Concernente à produção, Brasil, Colômbia e Etiópia são os maiores produtores mundiais do café arábica. Já o robusta é mais produzido em áreas úmidas em baixas altitudes no Vietnã, Indonésia e em Uganda. Cerca de $75 \%$ da produção global de café arábica e robusta é exportada, gerando um valor total de US $\$ 16$ bilhões para os países produtores (UN COMTRADE DATABASE, 2018).

Considerando a volatilidade dos preços e volumes, o valor médio anual das exportações foi de US\$20,2 bilhões no período 2010-2015. No entanto, esse número representa apenas $10 \%$ do valor total da indústria, que foi estimado em 2015 em cerca de US $\$ 200$ bilhões. Isto representa que apenas 10\% da riqueza agregada produzida pelo café permanece nos países produtores. Os países que importam, industrializam, registram patentes e comercializam o produto final ficam com a maior parte da renda do café exportado (SAMPER; GIOVANNUCCI; VIEIRA, 2017). Para a World Intellectual Property Organization (WIPO) (2017), porém, existe espaço para que os 
países produtores possam agregar valor ao grão, produzindo os chamados cafés especiais. Os grãos de café especiais podem receber um preço premium de cerca de 20 a 50\% em relação aos grãos de café normais (BART et al., 2014; TOLESSA et al., 2016).

Os cafés especiais são aqueles com alto padrão de qualidade. Esse padrão de qualidade, o mais amplamente aceito pelos profissionais de café no mundo, é baseado em um protocolo de prova composto por 11 critérios. Em uma escala de zero a 100 pontos, os cafés com pontuação maior que 80 são considerados especiais (SCAA, 2015). No entanto, outros atributos específicos associados ao produto, ao processo de produção ou ao serviço também podem caracterizar os cafés especiais, como: o aspecto dos grãos, a forma de colheita, o tipo de preparo, a adição ou retirada de alguns componentes, a história e a origem dos plantios, além da sustentabilidade econômica, ambiental e social da produção e da rastreabilidade dos grãos. Como alguns destes atributos não são facilmente identificados pelos consumidores, os cafés especiais são comumente certificados. São diversos os tipos de certificados ou certificações, entre eles: os de caráter ambiental, como orgânicos, sombreados e bird friendly (amigos dos pássaros); os socioambientais, como os de comércio justo e solidário; os de gestão e qualidade e as certificações ligadas à origem e indicação geográfica.

Dada esta diversidade de certificações e o potencial dos cafés especiais no mercado consumidor mundial, é importante conhecer o panorama e as perspectivas das pesquisas científicas com foco nas certificações para o café. Diante disso, este artigo tem como objetivo analisar a produção científica quanto ao tema certificação do café, apontando abordagens crescentes e potenciais e também as lacunas de pesquisa existentes na literatura, no que se configura como uma agenda de pesquisa para o futuro. Para isso, utiliza-se a bibliometria, em que foram considerados artigos publicados nos últimos 10 anos (2009 a 2019) da base de dados da Web of Science e os resultados analisados por meio do software VOSviewer.

\section{Certificação na cafeicultura mundial}

O café foi uma das primeiras commodities agrícolas a serem certificadas no comércio internacional e vários tipos de certificação são aplicados globalmente à cultura, como: o sistema Fairtrade, representado pela Fairtrade Labelling Organizations (FLO); o conjunto de certificações orgânicas - a Federação Internacional de Movimentos de Agricultura Orgânica, IFOAM, é o órgão normatizador; o sistema Rainforest Alliance (RAS) - a Rede de Agricultura Sustentável é o órgão normatizador; o sistema UTZ Certified - em que a normatizadora é a UTZ Kapeh e, por fim; o Bird Friendly - normatizada pelo instituto de pesquisa The Smithsonian Migratory Bird Center. (MELO et al., 2017). O Quadro 1, a seguir, traz a caracterização das principais certificações para o café. 
Quadro 1 - Síntese das características das principais certificações de café

\begin{tabular}{|c|c|c|c|c|c|}
\hline & Fairtrade & Orgânico & Rainforest Alliance & UTZ & Bird Friendly \\
\hline 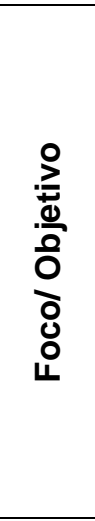 & $\begin{array}{l}\text { Melhorar a posição dos } \\
\text { pequenos agricultores, } \\
\text { garantindo preços } \\
\text { mínimos quando os } \\
\text { mercados estiverem em } \\
\text { baixa. Busca promover } \\
\text { relações de longo prazo } \\
\text { entre os importadores e } \\
\text { as cooperativas. Foca no } \\
\text { desenvolvimento dos } \\
\text { produtores e na redução } \\
\text { da pobreza. }\end{array}$ & $\begin{array}{l}\text { Desenvolver } \\
\text { padrões para a } \\
\text { agricultura } \\
\text { orgânica e facilitar } \\
\text { sua adoção. Unir o } \\
\text { movimento } \\
\text { orgânico em todo o } \\
\text { mundo. }\end{array}$ & $\begin{array}{lrr}\text { Melhorar } & 0 & \text { meio } \\
\text { ambiente } & \text { e } & \text { as } \\
\text { condições } & \text { sociais } & \text { em } \\
\text { agricultura } & \text { tropical, } \\
\text { ficando } & & \text { a } \\
\text { biodiversidade } & \text { e } & \text { a } \\
\text { sustentabilidade. } & \end{array}$ & \begin{tabular}{|lr} 
Possui normas & sociais, \\
ambientais & e \\
econômicas. & Busca \\
alcançar as cadeias de \\
fornecimento \\
sustentáveis, \\
encontrando rr as \\
necessidades & dos \\
agricultores, & da \\
indústria e & dos \\
consumidores. Visa \\
criar transparência ao \\
longo da cadeia e \\
recompensar & os \\
produtores de café \\
responsáveis.
\end{tabular} & 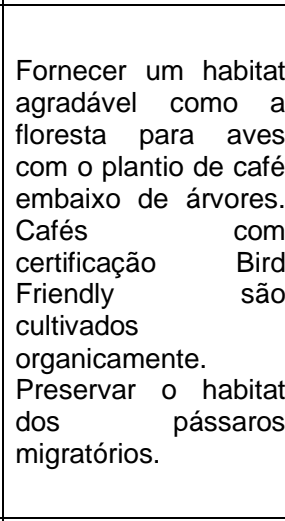 \\
\hline 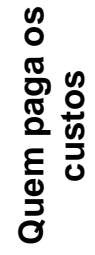 & $\begin{array}{l}\text { Os produtores pagam a } \\
\text { certificação e o } \\
\text { monitoramento dos } \\
\text { custos. A certificadora } \\
\text { fornece alguns subsídios } \\
\text { para compensar os } \\
\text { custos. }\end{array}$ & \begin{tabular}{|lr} 
Os r produtores \\
pagam & a \\
certificação & e \\
custos & de \\
monitoramento.
\end{tabular} & - & $\begin{array}{l}\text { Os produtores pagam } \\
\text { para inspeções anuais } \\
\text { por monitores de } \\
\text { terceiros aprovados } \\
\text { pela certificadora. }\end{array}$ & $\begin{array}{lr}\text { Produtores pagam a } \\
\text { certificação e os } \\
\text { custos } & \text { de } \\
\text { monitoramento. } & \\
\text { Certificação } & \text { de } \\
\text { orgânico } & \text { é } \\
\text { necessária. } & \end{array}$ \\
\hline 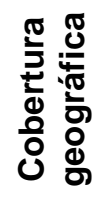 & $\begin{array}{l}\text { Global, mas grande } \\
\text { parte vem da África. } \\
\text { Pequenos produtores. }\end{array}$ & $\begin{array}{l}\text { Global, mas a } \\
\text { maioria do café } \\
\text { orgânico vem da } \\
\text { América Latina } \\
\text { (México). }\end{array}$ & $\begin{array}{l}\text { Somente países da } \\
\text { América Latina. } \\
\text { Certifica propriedades } \\
\text { e cooperativas. }\end{array}$ & $\begin{array}{l}\text { Países da América } \\
\text { Latina, Ásia e África. } \\
\text { Certifica propriedades } \\
\text { e cooperativas. }\end{array}$ & $\begin{array}{l}\text { Países da América } \\
\text { Latina. }\end{array}$ \\
\hline
\end{tabular}

Fonte: Adaptado de Melo et al. (2017).

De forma geral, essas certificações representam prêmios, pagos pela diferenciação do produto, agregados aos preços pagos aos agricultores pelo café especial. Para Bart et al. (2014) e Tolessa et al. (2016), os cafés orgânicos e de comércio justo, por exemplo, podem gerar um prêmio de cerca de $9 \%$ se comparado ao café comum. Já Samper, Giovannucci e Vieira (2017) apontam que os produtores de café especial vendem seus produtos por até US\$4,11 a libra-peso (unidade de medida usada pela Bolsa de Nova lorque equivalente a 453 gramas), enquanto que o grão comum é vendido, em média, a US\$1,25 por libra-peso. No entanto, não há consenso ainda na literatura se os agricultores recebem rendimentos significativamente mais altos. Enquanto alguns estudos argumentam que os agricultores que participam desse segmento de mercado recebem preços mais altos do que os produtores de café comum, outros estão menos convencidos devidos aos altos custos associados. Uma série de benefícios pode ser associada às certificações, como a melhor conservação ambiental e de recursos e melhores práticas de trabalho (SAMPER; GIOVANNUCCI; VIEIRA, 2017). Muitos autores já identificaram, no entanto, que, entre os produtores, a principal razão para certificação do café é a motivação econômica (FISCHER; QAIM, 2014, OYA et al., 2017, PYK; HATAB, 2018).

Os sistemas de certificação de café foram lançados na década de 1980 e, desde então, há um volume crescente de literatura sobre os impactos destas certificações sobre os cafeicultores (CHIPUTWA; QAIM; SPIELMAN, 2015). No entanto, poucos são os estudos que fornecem uma análise da literatura científica sobre certificação através de ferramentas bibliométricas. Os trabalhos que utilizam 
esta ferramenta concentram suas pesquisas ou sobre alguma certificação específica ou sem delimitar um produto. Barros et al. (2015), por exemplo, utilizaram métodos bibliométricos para empregar uma análise de desempenho sobre a literatura internacional sobre comércio justo. Do mesmo modo, Ruggeri, Orsi e Corsi (2018) realizaram um mapeamento abrangente da ciência também sobre comércio justo. Ambos encontraram uma prevalência de estudos sobre certificação em produtos agrícolas (especialmente café), demonstrando a importância e a necessidade de se utilizar a bibliometria em um estudo específico para a cadeia do café. Já Melo et al. (2017) fizeram uma revisão sistemática na cafeicultura, no entanto, os autores analisaram apenas as publicações sobre certificação sustentável do grão.

\section{Metodologia}

A metodologia deste estudo baseia-se em pesquisa exploratória, que utilizou a bibliometria como principal ferramenta metodológica. A fonte de dados utilizada foi a Web of Science (WoS), base de dados multidisciplinar da Thomson Reuters, usada mundialmente para a realização de análises da produção científica. A WoS foi escolhida como a base a ser consultada por ser multidisciplinar e indexar os periódicos mais citados em suas respectivas áreas. Atualmente, ela possui mais de 18.000 periódicos indexados (CLARIVATE ANALYTICS, 2019).

Houve restrição ao tipo e ao período das publicações, assim buscaram-se apenas artigos publicados de 2009 a 2019. Na coleta dos dados, empregou-se a opção de busca avançada. As palavras-chave foram escolhidas com o intuito de analisar as características das publicações sobre certificação e café. Assim, empregou-se o campo TS (Tópico), referente ao tópico da pesquisa e foi construída a seguinte expressão de busca: $(T S=$ (certification AND coffee OR coffee production OR coffee chain)). Uma busca inicial, no entanto, foi realizada anteriormente para se conhecer as principais temáticas estudadas nas publicações sobre café. Para essa busca inicial foi construída a seguinte expressão de busca: (TS= (coffee OR coffee production OR coffee chain)).

As coletas de dados foram realizadas em março de 2019 e foram encontradas 16.655 publicações sobre café e 791 publicações sobre café e certificação. Os dados foram importados da Web of Science em arquivos em formato txt. Para organização e análise dos dados foi utilizado o software VOSviewer, de domínio público, desenvolvido pelo Centro de Estudos de Ciência e Tecnologia da Universidade de Leiden, Holanda. A ferramenta permite a organização e a realização de análises descritivas dos registros bibliográficos extraídos de bases de dados como a WoS.

Em estudos biliométricos diferentes ferramentas podem ser usadas para construir e visualizar mapas bibliométricos, tais como Pajek, VOSviewer, Mapequation, Netdraw, UCINET e outras. Com o VOSviewer, os mapas podem ser criados a partir de dados de rede, usando técnicas de mapeamento e agrupamento. O software permite que clusters sejam criados por agrupamentos e pode ser usado para construir mapas de autores ou periódicos (com base na cocitação de dados) ou para a construção de mapas de palavras-chave (com base em dados de coocorrência).

O VOSviewer desenvolve um processo de agrupamento através da implementação do algoritmo de mapeamento VOS, que minimiza a distância entre 
elementos semelhantes. A força de associação de coocorrências é medida pelo número de vezes que a palavra aparece. Para cada ocorrência, os termos mais relevantes são selecionados com base no número de vezes que foram citados (VAN ECK; WALTMAN, 2010). Segundo o VOSviewer, se duas ou mais palavras são citadas juntas em uma publicação, estas palavras são relacionadas. Quanto maior o número de vezes que elas ocorrem juntas, maior a força da coocorrência.

Desta forma, pode-se identificar os termos mais frequentemente utilizados em temas de pesquisa. Os clusters de palavras são formados pelas palavras que aparecem nos títulos, resumos ou palavras-chave das publicações. O tamanho de um cluster reflete o número de publicações pertencentes a este ou a frequência em que as palavras ocorrem. A distância entre dois clusters indica aproximadamente a proximidade destes em termos de ocorrência. Clusters localizados próximos um do outro tendem a ser fortemente relacionados, enquanto os que estão localizados longe um do outro tendem a ser menos fortemente relacionados (VAN ECK; WALTMAN, 2017).

Ao final, os resultados das análises bibliométricas permitem ampliar a compreensão sobre o que se pesquisa, no caso deste estudo certificações de café. A partir desta identificação é possível caracterizar as redes de colaboração, bem como mapear a evolução dos diferentes campos de estudo sobre café e traçar agenda de pesquisa.

\section{Resultados e Discussões}

\subsection{Pesquisas sobre café: principais temáticas}

Os resultados encontrados mostram 16.655 publicações sobre o tema café na Web of Science para o período estudado. A primeira análise realizada é a de ocorrência de palavras, com o objetivo de identificar as principais temáticas abordadas nos estudos sobre café no mundo. A Figura 1, a seguir, apresenta um mapa com as palavras que mais ocorrem nos títulos, resumos e palavras-chave dos trabalhos.

Figura 1 - Mapa das palavras que ocorrem nos títulos, resumos e palavras-chave das publicações sobre café.

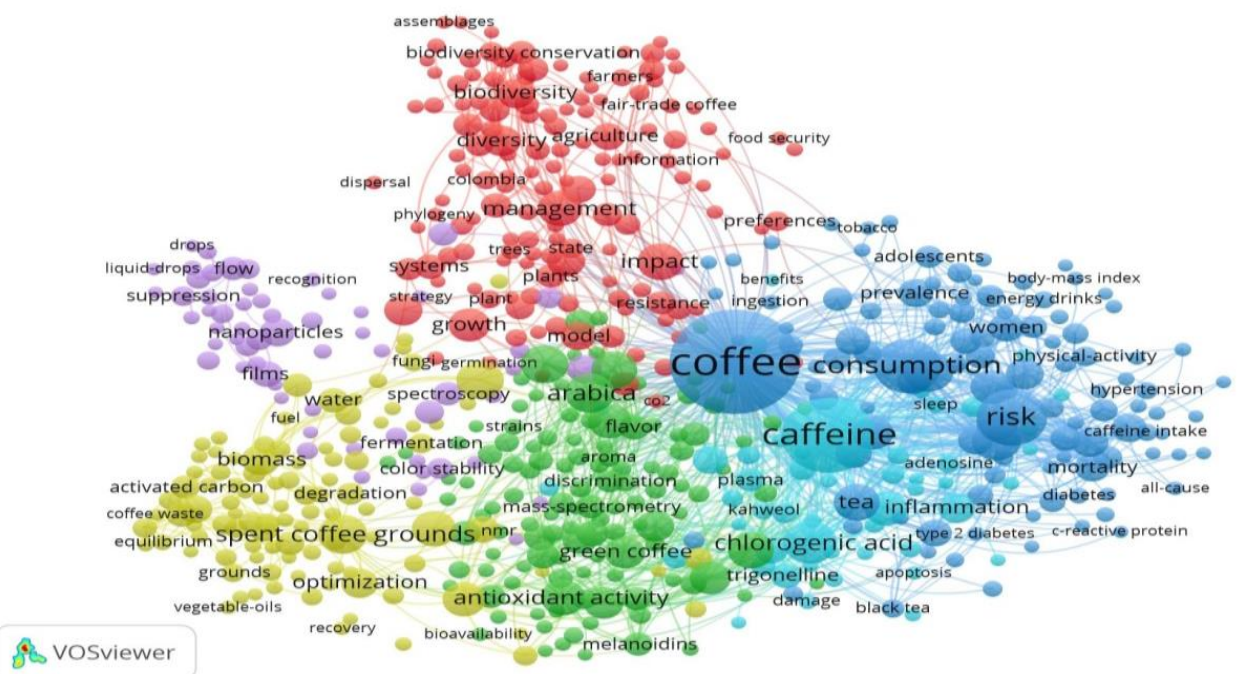

Fonte: Elaborado pelos autores com dados de Web of Science. 
As palavras (Figura 1) são apresentadas em forma de agrupamentos ou clusters, com diferentes cores e tamanhos, referentes à recorrência das palavras e respectivas áreas da ciência. Observa-se que seis clusters são identificados e aqueles que aparecem próximos compartilham de alta similaridade, enquanto que os clusters mais afastados denotam baixa similaridade. Cada círculo constituinte da rede é uma das 585 palavras que tiveram cinco ou mais ocorrências.

As palavras "coffee" e "caffeine" são as que aparecem em tamanho maior, e ocorreram 362 e 186 vezes, respectivamente, nas publicações. No cluster de cor azul escuro, em que aparece a palavra "coffee", aparecem relacionadas a ela palavras como "consumption", "risk", "tea", "health" e "adults". No cluster de cor azul claro, ligados à palavra "caffeine", aparecem também palavras como "chlorogenic acid", "inflammation" e "oxidative stress". Além delas, aparecem em outros três clusters de cores diferentes, palavras como: "arabica", "green coffee", "antioxidant activity", "flavor", "aroma" (no cluster verde); "spent coffee grounds", "optimization", "biomass", "extraction", "phenolic-compounds" (no cluster amarelo); "nanoparticles", "films", "supression", "color stability", "flow" (no cluster roxo) e "management", "diversity", "impact", "systems", "biodiversity", "growth" (no cluster vermelho).

A partir desta clusterização, entende-se que, no cluster de cor azul escuro, o foco das publicações é o consumo de café relacionado à saúde. No de cor azul claro destacam-se estudos sobre compostos encontrados no café, como a cafeína e o ácido clorogênico, e sua influência na saúde humana, como no tratamento de doenças. Juntos, os clusters azul escuro e azul claro, que têm termos referentes ao consumo de café, seus compostos e saúde, apresentaram $27 \%$ das palavras encontradas (110 e 50 palavras, respectivamente). Já no de cor verde esses compostos estão relacionados com seu efeito no sabor e no aroma do café. O cluster verde apresentou $21 \%$ das palavras encontradas. No de cor amarelo, o foco dos estudos são os resíduos do café (como as spent coffee grounds) e suas formas de tratamento e utilização. No cluster roxo, os estudos concentram-se nas propriedades químicas e físicas do café e nos fatores que podem alterar essas propriedades, como as nanopartículas, por exemplo. Os clusters amarelo e roxo, que tratam dos resíduos do café e das propriedades químicas e físicas da bebida, apresentaram 17\% e 11\% do total de palavras cada um. Por último, no cluster vermelho, as publicações tratam sobre questões socioeconômicas, como a conservação da biodiversidade, a sustentabilidade, o comércio justo, o mercado e, por fim a certificação. A Tabela 1 abaixo resume as temáticas.

Tabela 1 - Principais temáticas de pesquisa e sua recorrência (em \% do total)

\begin{tabular}{c|c|c|c|c|c|c}
\hline Cluster & Azul escuro & Azul claro & Verde & Amarelo & Roxo & Vermelho \\
\hline Temática & $\begin{array}{c}\text { Café e } \\
\text { Saúde }\end{array}$ & $\begin{array}{c}\text { Café e } \\
\text { Saúde }\end{array}$ & $\begin{array}{c}\text { Sabor } \\
\mathrm{e} \\
\text { Aroma }\end{array}$ & Resíduos & $\begin{array}{c}\text { Propriedades } \\
\text { Químicas e } \\
\text { Físicas }\end{array}$ & $\begin{array}{c}\text { Estudos } \\
\text { Socioeconômicos e } \\
\text { Ambientais }\end{array}$ \\
\hline No. de palavras & 110 & 50 & 121 & 102 & 62 & 140 \\
\hline$\%$ & \multicolumn{2}{|c|}{$27 \%$} & $21 \%$ & $17 \%$ & $11 \%$ & $24 \%$ \\
\hline
\end{tabular}

Fonte: Elaborado pelos autores com dados de Web of Science.

Os resultados apontam (Tabela 1) que das 585 palavras encontradas, 24\% delas (140 palavras) ocorreram no cluster vermelho, que trata sobre fatores socioeconômicos. Isto indica que o cluster vermelho - que trata do tema da certificação - é o que apresenta a maior diversidade de termos nas publicações. Uma 
justificativa para esta diversidade é o caráter multidisciplinar dos estudos socioeconômicos à qual a certificação pertence. Ruggeri, Orsi e Corsi (2018), ao realizarem uma pesquisa bibliométrica sobre certificação fairtrade, também encontraram estudos muito plurais sobre o tema, caracterizando-a como uma área de pesquisa multidisciplinar. Os estudos sobre certificação consideram desde os que analisam aspectos relacionados aos agricultores às formas de cultivo e manejo da biodiversidade até aqueles com foco nos consumidores e suas preferências. Com destaque para esse agrupamento, apresenta-se a Tabela 2 , na sequência, que traz as 25 palavras mais frequentes no cluster vermelho.

Tabela 2 - Resumo das palavras mais frequentes no cluster vermelho

\begin{tabular}{l|c|l|c}
\hline Palavra & No. de ocorrências & Palavra & No. de ocorrências \\
\hline management & 42 & resistance & 19 \\
growth & 37 & biodiversity conservation & 18 \\
coffe arabica & 33 & plants & 18 \\
diversity & 33 & system & 18 \\
biodiversity & 30 & yield & 18 \\
agriculture & 25 & coffee berry borer & 17 \\
sustainability & 24 & arabica coffee & 16 \\
climate-change & 21 & soil & 16 \\
conservation & 21 & ecosystem services & 15 \\
forest & 21 & fair trade & 15 \\
systems & 21 & certification & 13 \\
agroforestry & 19 & willingness-to-pay & 12 \\
brazil & 19 & & \\
\hline
\end{tabular}

Fonte: Elaborado pelos autores com dados de Web of Science.

Pode-se obervar que as palavras mais frequentes (Tabela 2) são aquelas ligadas à dimensão agrícola e ambiental, demonstrando que os estudos deste cluster tem enfoque maior no meio ambiente, na agricultura e conservação da biodiversidade e das florestas, por exemplo, que propriamente aspectos econômicos e sociais. É importante observar também que o Brasil (termo "brazil') aparece como objeto de pesquisa deste cluster, destacando a preocupação com o ambiente e com o processo de produção do café cultivado no país. Além disso, isto corrobora os resultados encontrados por Bray e Neilson (2017). Segundo os autores, que analisaram 51 trabalhos sobre certificação de café produzidos nos últimos 15 anos, a maioria deles tem como objeto de estudo os países produtores de café. A América Central compôs trinta desses estudos, a América do Sul seis, a África onze e a Ásia três.

Com relação à questão econômica (Tabela 2), as palavras "fair trade", "certification" e "willingness-to-pay" são as que mais ocorrem, com 15, 13 e 12 ocorrências cada uma, respectivamente. A frequência desses três termos pode ser justificada pelo interesse em conhecer ainda mais a receptividade dos consumidores frente aos cafés certificados. Estudos anteriores já demonstraram que a maioria dos consumidores é muito receptiva aos rótulos éticos, como as certificações fairtrade, e os de denominação de origem (PELSMACKER; DRIESEN; RAYP, 2005). Os consumidores estariam dispostos inclusive a pagar prêmios por essas certificações, com valores ainda mais altos do que para produtos orgânicos ou outros tipos de certificações, como o café cultivado à sombra e o café orgânico (LOUREIRO; LOTADE, 2005; BALLESTERO et al., 2019).

Apesar da grande quantidade de palavras e do tamanho do cluster vermelho, os clusters azuis (claro e escuro) são os que detêm as palavras que apareceram mais vezes nas publicações. A Figura 2 apresenta a densidade dos termos. A cor amarela 
e também o tamanho da letra indicam maior densidade, o que sinaliza que essas palavras têm maior ocorrência dentro das publicações.

Figura 2 - Mapa de densidade das palavras que ocorrem nos títulos e resumos e palavras-chave das publicações

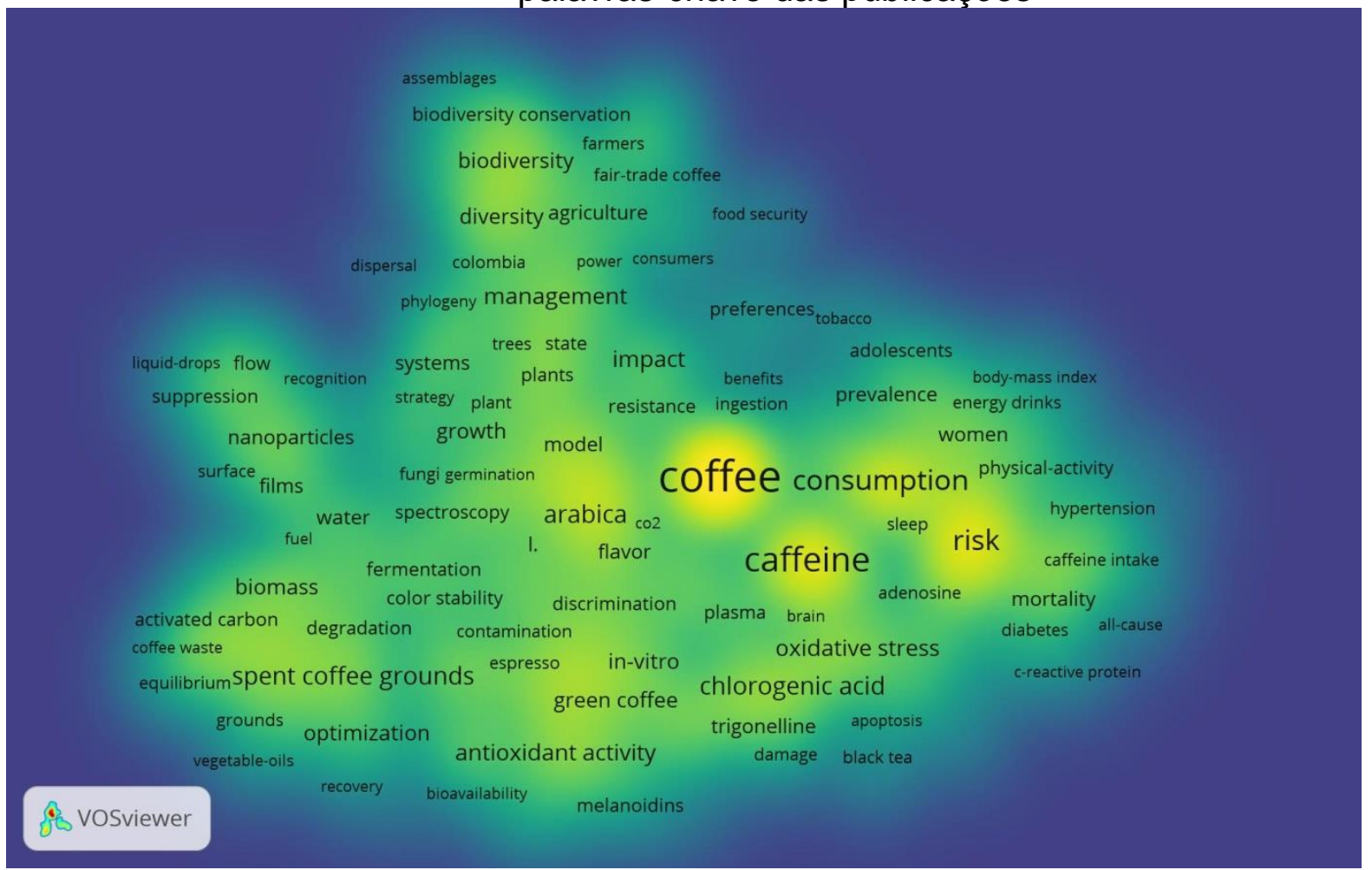

Fonte: Elaborado pelos autores com dados de Web of Science.

Destaca-se, portanto, o consumo de café e sua relação com a saúde como o foco principal das discussões sobre café no período analisado, visto que as palavras "coffee", "caffeine", "consumption" e "risk" são as que mais aparecem nas publicações. Ao longo das últimas décadas muitos estudos foram realizados com o objetivo de esclarecer a relação entre o consumo da bebida e da cafeína e seus efeitos na saúde humana (MARTINI et al., 2016). Na área da saúde, algumas linhas de investigação apontam para um efeito benéfico do café, inclusive no tratamento de determinadas doenças (RAMALHO; SOARES, 2018); no entanto, outros estudos descrevem a possibilidade de o consumo de café provocar dependência e/ou ser prejudicial a alguns grupos da população (DE MARIA; GOMIDE, 2019). Sendo assim, muitos resultados ainda são inconclusivos, visto a enorme variabilidade interindividual e a preferência por diferentes tipos de bebidas de café, com variações desde as espécies (arábica e/ou robusta), graus de torra e moagem e método de preparação da mesma, que dificultam frequentemente a comparação entre os variados estudos (DA SILVA et al., 2018). Deste modo, isto pode despertar cada vez mais a atenção da comunidade científica, além de justificar o interesse pelo tema e, consequentemente, a grande ocorrência desses termos nas publicações sobre café no período analisado.

Assim, concernente à pesquisa da palavra café, observa-se que os estudos são mais abundantes e recorrentes nas áreas da saúde, aspectos químicos e de componentes da bebida. Referente aos aspectos socioeconômicos, destaca-se que os estudos têm foco na questão ambiental e de preservação. 


\subsection{Café \& Certificação: sobre o que são os estudos?}

Com o objetivo de aprofundar a análise das publicações sobre certificação, a Figura 3 apresenta um mapa com as palavras que mais ocorrem nos títulos, resumos e palavras-chave das 791 publicações encontradas sobre certificação e café. Cada círculo constituinte da rede é uma das 265 palavras que tiveram cinco ou mais ocorrências.

Figura 3 - Mapa das palavras que ocorrem nos títulos, resumos e palavras-chave das publicações sobre certificação e café.

VOSviewer

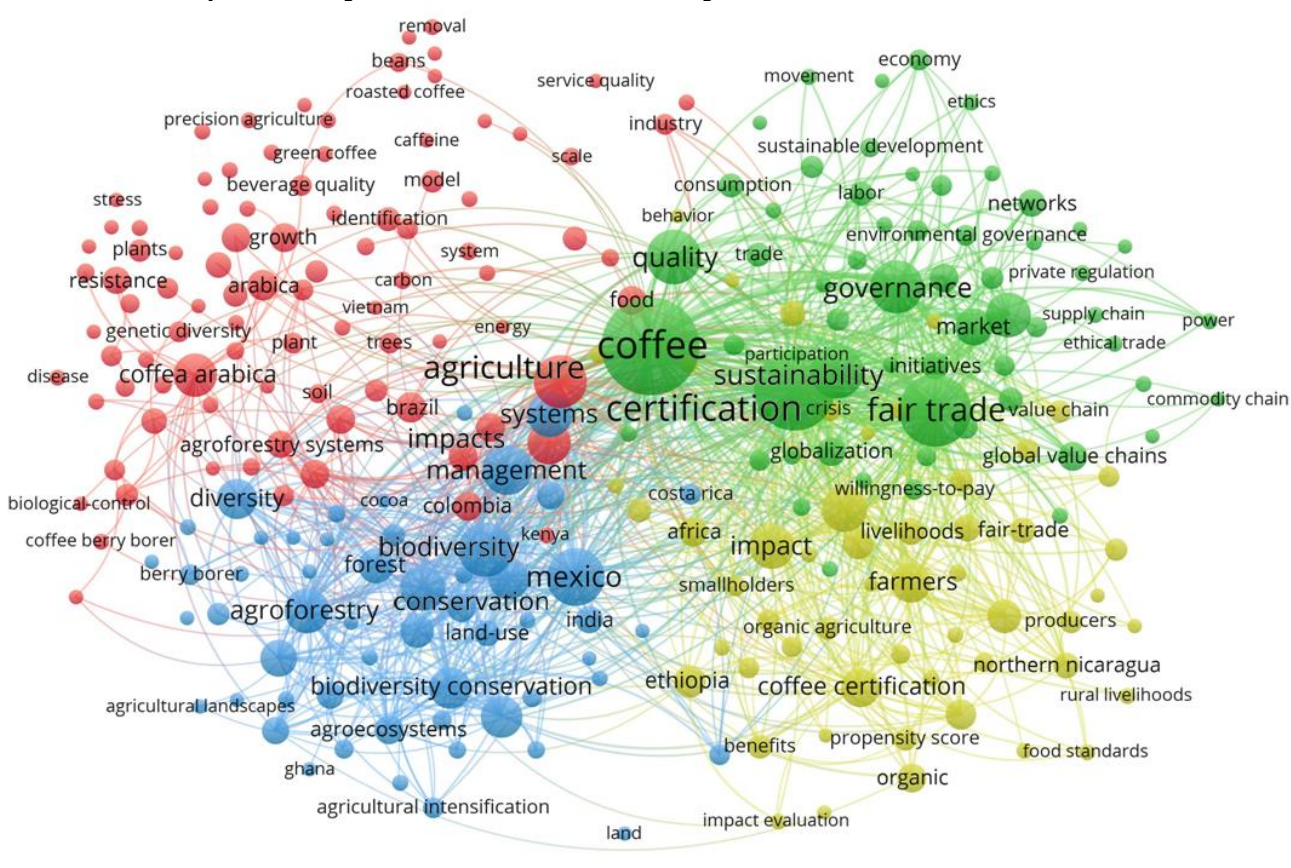

Fonte: Elaborado pelos autores com dados de Web of Science.

Nos estudos sobre certificação do café é possível observar quatro clusters diferentes, ou seja, quatro temáticas de estudo sobre o tema. No cluster de cor amarela aparecem palavras como "impact", "farmers", "coffee certification", "Iivelihoods", "ethiopia", "africa", "nicaragua". No cluster azul aparecem palavras como "biodiversity", "management", "agroforesty", "systems". No cluster vermelho é possível observar palavras como "agriculture", "impacts", "growth", "resistance", "plants", "brazil", "colombia". Por fim, no último cluster, de cor verde, aparecem palavras como: "certification", "fair trade", "governance", "sustainability", "quality", "market", "globalization".

A partir desta clusterização, entende-se que, no cluster de cor amarela, o foco das publicações é no impacto que a certificação pode (ou não) desempenhar para os agricultores, com destaque para estudos sobre países em desenvolvimento, como Etiópia e Nicarágua. No azul, o foco são estudos sobre a certificação e sua influência na conservação da biodiversidade, do ecossistema e das florestas, por exemplo, com destaque para países como México e Índia. Já no cluster vermelho, as publicações abordam assuntos sobre a certificação e a qualidade do café frente às diferentes práticas agrícolas, por exemplo, com estudos sobre pragas e doenças que podem 
afetar a produção e também a qualidade da bebida. O Brasil e a Colômbia são objetos de estudo neste cluster. Por fim, no cluster verde, o foco dos estudos é a certificação e o comportamento do mercado mundial de cafés certificados, assim como as relações entre os elos da cadeia do café. A Tabela 3, na sequência, resume as principais temáticas encontradas nas publicações sobre certificação e café.

Tabela 3 - Principais temáticas de cada cluster e sua recorrência (em \% do total)

\begin{tabular}{c|c|c|c|c}
\hline Cluster & Amarelo & Azul & Vermelho & Verde \\
\hline Temática & $\begin{array}{c}\text { Impacto das } \\
\text { certificações junto aos } \\
\text { agricultores }\end{array}$ & $\begin{array}{c}\text { Certificação e } \\
\text { biodiversidade }\end{array}$ & $\begin{array}{c}\text { Certificação e } \\
\text { qualidade da } \\
\text { bebida }\end{array}$ & $\begin{array}{c}\text { Certificação e } \\
\text { mercado }\end{array}$ \\
\hline No. de palavras & 54 & 55 & 94 & 62 \\
\hline$\%$ & $21 \%$ & $21 \%$ & $35 \%$ & $23 \%$ \\
\hline
\end{tabular}

Fonte: Elaborado pelos autores com dados de Web of Science.

Os resultados (Tabela 3 ) indicam que a temática da certificação do café pode ter diversas abordagens. Como a certificação pode interferir em diferentes elos da cadeia produtiva do grão (desde os agricultores, processadores, cooperativas, torrefadores até os distribuidores e consumidores) e sobre diversos aspectos, portanto, pesquisas com recortes específicos e distintos são frequentes. De todo modo, é possível observar que, nas publicações sobre certificação, a preocupação com a qualidade do café predomina nos estudos (35\% deles). Em seguida, a preocupação com a biodiversidade e o impacto das certificações junto aos agricultores são responsáveis por $21 \%$ das publicações cada um. E, por fim, $23 \%$ dos estudos são relacionados às questões de mercado que envolvem as certificações da bebida. Estes resultados corroboram os encontrados por Ballestero et al. (2019) em estudo sobre os fatores que impactam no comportamento do consumidor de cafés certificados. Segundo os autores, o consumidor busca a saudabilidade nos cafés certificados, além de preferirem embalagens mais chamativas, que possam associar produtos e informações a partir das mesmas (como as relacionadas ao processo produtivo). No entanto, os autores destacam que, do ponto de vista do consumo, a intenção de compra diminui à medida que o preço do produto em si aumenta e apenas uma parcela dos consumidores - engajados - está disposta a pagar mais pelo produto certificado. A seguir, a Tabela 4 apresenta um resumo com as 25 palavras mais frequentes nas publicações analisadas.

Tabela 4 - Resumo das palavras mais frequentes nos títulos, resumos e palavraschave

\begin{tabular}{l|c|l|c}
\hline \multicolumn{1}{c|}{ Palavra } & No. de ocorrências & \multicolumn{1}{|c}{ Palavra } & No. de ocorrências \\
\hline coffee & 222 & systems & 47 \\
certification & 185 & conservation & 47 \\
fair trade & 122 & nicaragua & 46 \\
mexico & 79 & coffee production & 44 \\
biodiversity & 71 & coffea arabica & 43 \\
quality & 68 & biodiversity conservation & 42 \\
governance & 66 & shade coffee & 40 \\
sustainability & 65 & farmers & 39 \\
agriculture & 64 & costa-rica & 38 \\
management & 57 & diversity & 38
\end{tabular}

REUNA, Belo Horizonte - MG, Brasil, v. 25, n. 2, p. I-19, Abr. - Jun. 2020 - ISSN 2179-8834 


\begin{tabular}{l|l|l|l} 
agroforestry & 49 & market & 32 \\
standards & 48 & plantation & 32 \\
impact & 47 & & \\
\hline
\end{tabular}

Fonte: Elaborado pelos autores com dados de Web of Science

É possível observar (Tabela 4) que nas 791 publicações sobre certificação do café, os termos "comércio justo", "México", "biodiversidade", "qualidade" e "governança" são os mais aparecem nos estudos. Para Ruggeri, Orsi e Corsi (2018), muitos pesquisadores são confiantes sobre a contribuição que a certificação de comércio justo pode trazer para melhorar as condições de vida e os direitos trabalhistas de produtores e trabalhadores desfavorecidos. Podhorsky (2015) também demonstrou que a certificação fairtrade contribui para melhorar a renda do cafeicultor e para diminuição do poder dos agentes intermediários no mercado de café, o que justifica mais estudos sobre esta certificação frente às demais. O México, a Nicarágua e a Costa Rica são os países mais estudados nas publicações.

Além de bastante diversas, as publicações sobre certificação de café vêm crescendo ao longo dos anos. A crescente demanda pela bebida no mundo parece impulsionar também os estudos sobre o tema. A Figura 4 apresenta a evolução no número de publicações indexadas na Web of Science nos últimos 10 anos (2009 a 2019).

Figura 4 - Evolução no número de publicações indexadas na Web of Science de 2009 a 2019.

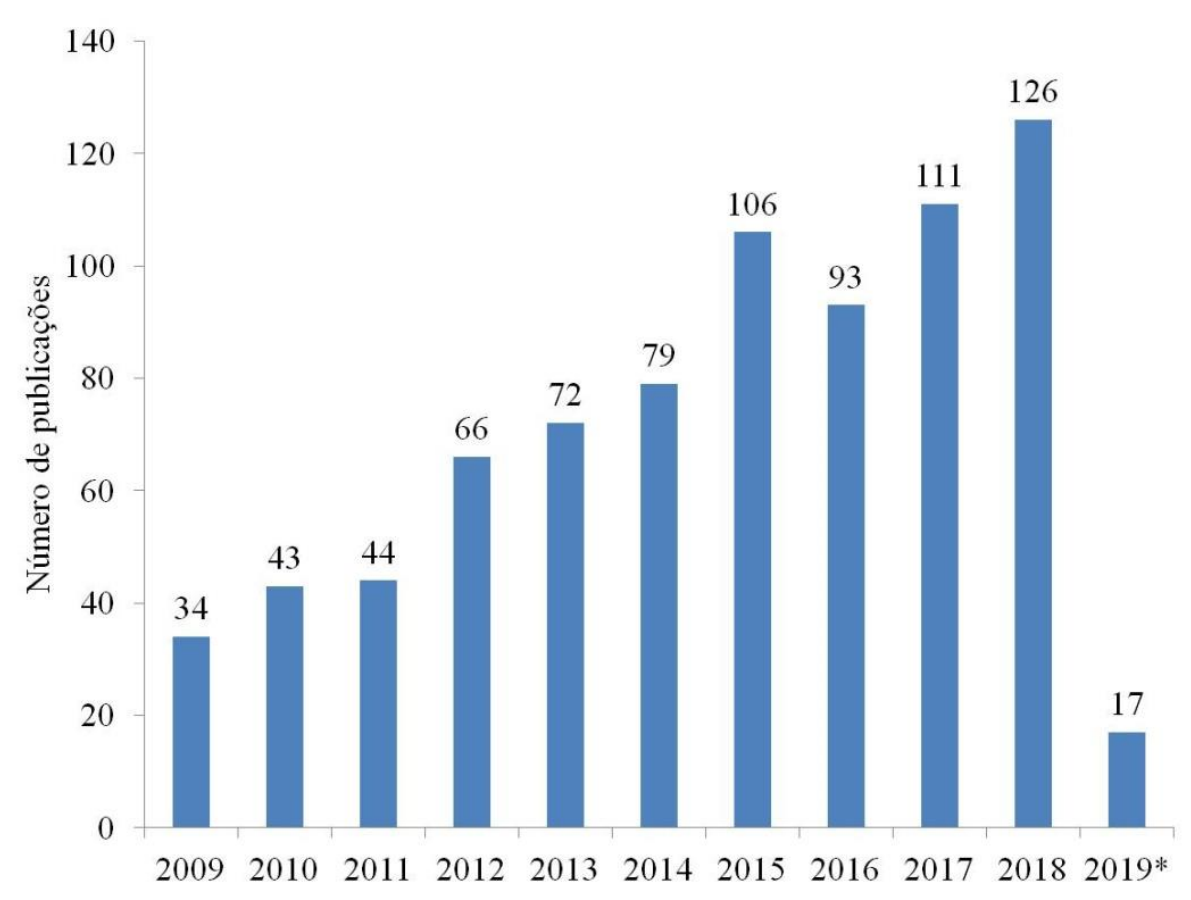

* O ano de 2019 foi analisado até o mês de março, quando ocorreu a coleta na base de dados.

Fonte: Elaborado pelos autores com dados de Web of Science (2019).

Nota-se (Figura 4) que as publicações sobre certificação do café mais que triplicaram em menos de 10 anos, de 2009 a 2018. Além disso, o crescimento vem 
sendo significativo ao longo dos anos, o que significa que a temática é nova e emergente. A produção do grão também se expandiu com relativa rapidez durante esse período, assim como a demanda mundial por variedades de café de alta qualidade (ROHDE; CASTAGNA, 2016). Apenas em 2016 as publicações sobre o tema apresentaram uma ligeira queda.

Com relação às áreas do conhecimento, as publicações podem ser divididas, de acordo com a Web of Science, em seis grandes áreas. A Figura 5 apresenta essas áreas e a distribuição das publicações para o período de 2009 a 2019.

Figura 5 - Áreas do conhecimento das publicações sobre certificação do café para o período de 2009 a 2019.

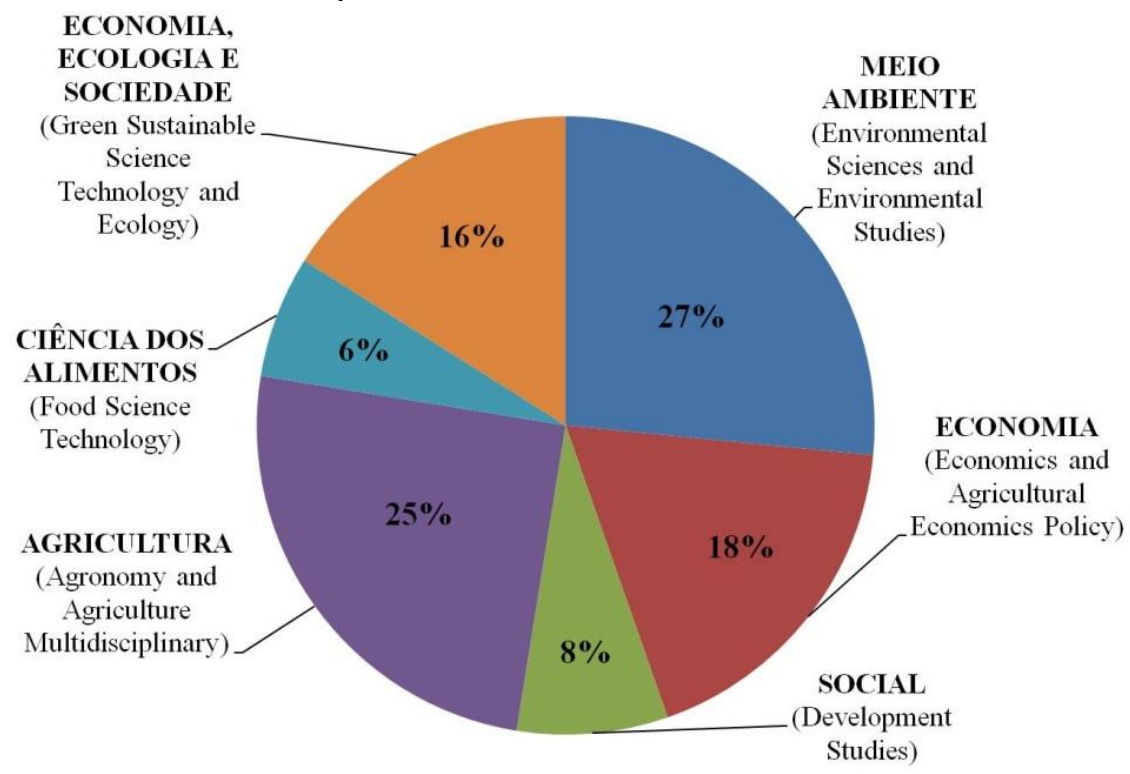

Fonte: Elaborado pelos autores com dados de Web of Science.

A maior parte das publicações analisadas no período (cerca de $27 \%$ do total) é da área de Meio Ambiente. Do mesmo modo, uma em cada quatro publicações são sobre Agricultura - no contexto agronômico. Juntos, Meio Ambiente e Agronomia representam $52 \%$ das publicações. Na sequência, $18 \%$ das publicações são da área econômica e $16 \%$ pesquisam sobre o tripé "economia, ecologia e sociedade". Por fim, apenas $8 \%$ pesquisam sobre questões estritamente sociais e $6 \%$ sobre a ciência dos alimentos.

Apesar de haver uma divisão entre as áreas de conhecimento, alguns estudos parecem permear e poderiam ser facilmente encaixados em mais de uma área de conhecimento, como os estudos sobre "economia, ecologia e sociedade" e também os sociais e/ou econômicos. Assim, conforme já observado nas clusterizações, dada a multidisciplinaridade do tema pesquisado (certificação de café), diversas abordagens e recortes podem ser realizados e, consequentemente, aplicados a mais de uma área do conhecimento.

Na Figura 6 há a apresentação do mapa com os países que mais pesquisam cientificamente sobre a temática para o período em análise. Dos 74 países que pesquisam sobre certificação do café, 58 deles têm pelo menos duas publicações sobre o tema e são apresentados abaixo. 
Figura 6 - Países que mais pesquisaram sobre certificação de café no período analisado.

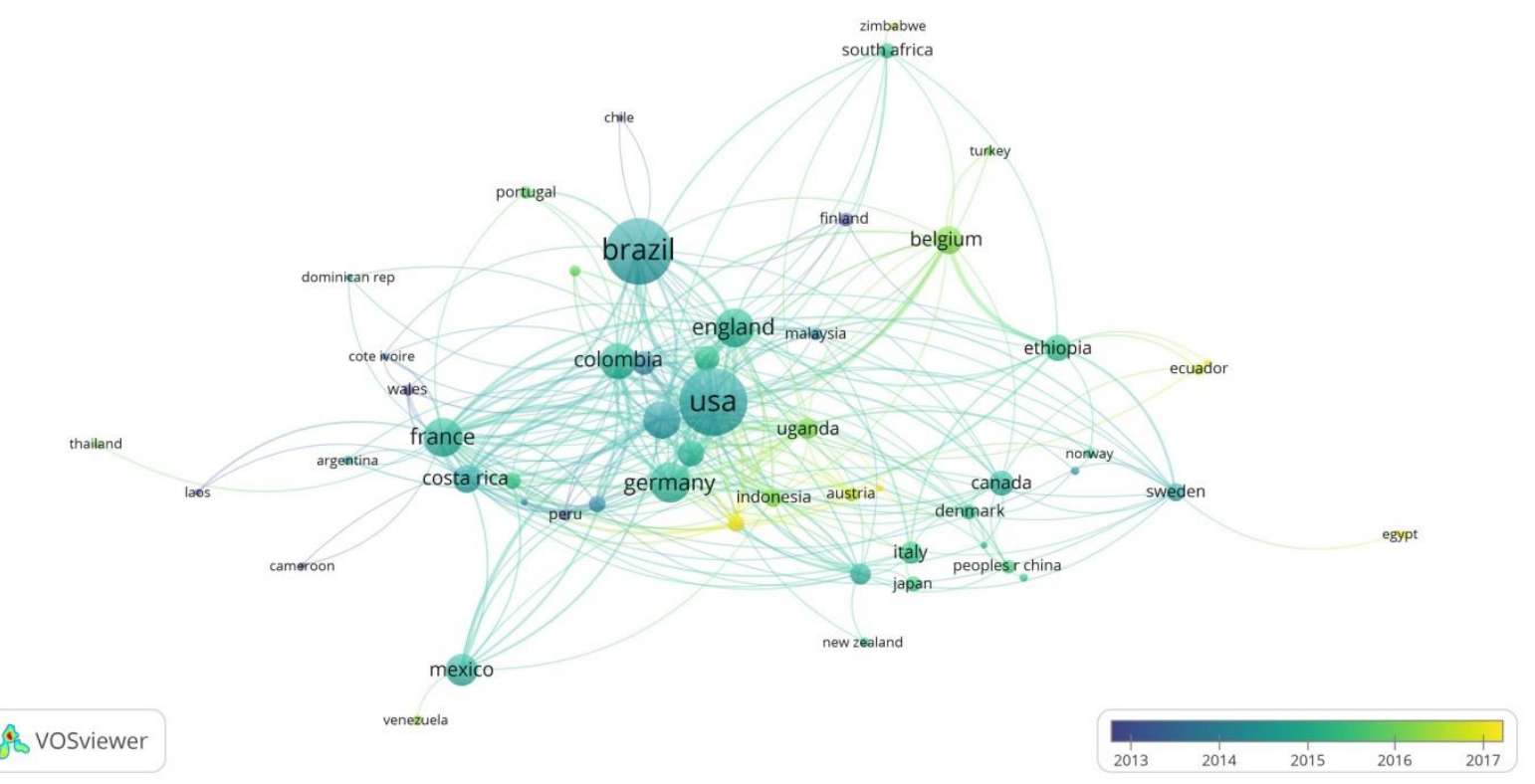

Fonte: Elaborado pelos autores com dados de Web of Science.

Estados Unidos e Brasil se destacam em número de publicações (171 e 167, respectivamente). Essa expressividade nos estudos dos dois países pode se justificar pelo fato dos Estados Unidos serem um dos maiores importadores mundiais de café, perdendo apenas para os países da União Européia, e o Brasil ser o maior exportador do grão (ICO, 2019). Do mesmo modo, Alemanha, Inglaterra, França e Holanda apresentam 66, 62, 61 e 57 publicações, respectivamente. Esses países são importadores de café e fazem parte da conhecida via de comércio mundial de café, que se dá entre os países produtores de café com níveis de renda baixo ou médio e os países desenvolvidos, com moderna tecnologia de processamento e altos níveis de renda per capita (CALDARELLI; GILIO; ZILBERMAN, 2019). Já a Colômbia tem 56 publicações. A área de café certificado da Colômbia cresceu sobremaneira nos últimos anos (HAGGAR et al., 2017) e pode justificar o interesse pelo tema. Além dessas questões, outros fatos chamam a atenção na análise sobre os países que mais publicaram sobre a certificação de café. A partir de 2016, Vietnã, Gana, Equador, Uganda e Indonésia também passaram a publicar sobre certificação do café.

Em 2015, Vietnã e Indonésia produziram 25\% do café do mundo (EMBRAPA, 2016). Já a produção de café na África na safra $2018 / 2019$ aumentou $1,4 \%$ em relação ao ano anterior, tornando o continente responsável por mais de $10 \%$ da safra mundial do grão (CONSÓRCIO PESQUISA CAFÉ, 2019). O mesmo acontece com o Equador que, na última safra, também teve sua produção de café aumentada em $24,4 \%$ com relação à safra 2017/18 (CONSELHO NACIONAL DO CAFÉ, 2018). Os dados demonstram que, além de aumentarem suas produções de café nos últimos anos, esses países estão preocupados com a qualidade da bebida e realizando estudos sobre a certificação do grão.

Quanto às principais organizações que pesquisam sobre certificação de café nos países, foram encontradas 993 delas. Apenas 279, no entanto, apresentam no mínimo duas publicações e estão ilustradas na Figura 7. 
Figura 7 - Instituições com pesquisas publicadas na Web of Science sobre café e certificação no período de 2009 a 2019.

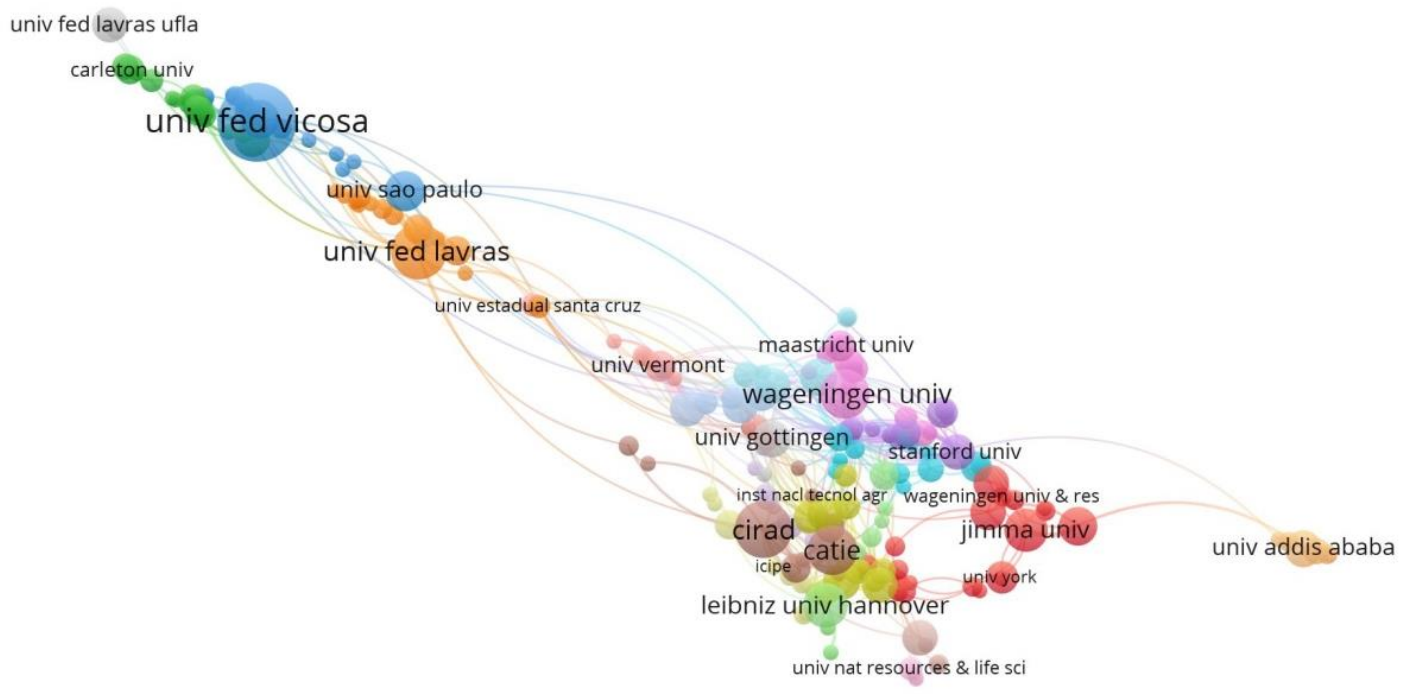

VOSviewer

Fonte: Elaborado pelos autores com dados de Web of Science.

As instituições que mais apresentaram publicações sobre o tema foram a Universidade Federal de Viçosa, no Brasil, e Centro Francês de Pesquisa Agrícola para o Desenvolvimento Internacional (CIRAD), com 44 e 23 publicações, respectivamente. Na sequência, a Universidade Federal de Lavras, também no Brasil, o Centro Agronômico Tropical de Pesquisa e Ensino Superior (CATIE), na Costa Rica, e a Universidade de Wageningen, na Holanda, aparecem com 22, 18 e 18 publicações cada uma.

As universidades brasileiras, especialmente as mineiras, têm se mostrado importantes centros de pesquisa sobre certificação de café. Isto pode ser explicado pelo fato de Minas Gerais concentrar a maior área com café arábica, 1,21 milhão de hectares, correspondendo a $69,6 \%$ da área ocupada no Brasil (COMPANHIA NACIONAL DE ABASTECIMENTO - CONAB, 2019). Vale destacar que o CIRAD é um importante parceiro das pesquisas brasileiras sobre café. Esse instituto atua há de mais de 25 anos com as equipes de pesquisa brasileiras, como a Embrapa, universidades, cooperativas, grupos de produtores e poderes públicos. Em 2004, a equipe do CIRAD no Brasil era constituída de 30 pesquisadores permanentes (EMBRAPA, 2004).

Entre os autores que mais publicam sobre a temática certificação de café, o VOSviewer encontrou 2456 autores. Destes, no entanto, apenas 316 autores tinham mais de duas publicações sobre o tema, ou seja, $87 \%$ dos pesquisadores só tem uma publicação nos últimos 10 anos sobre certificação de café. Como a temática pode ser considerada nova nas publicações, isto pode justificar a pouca frequência desta nas publicações de um mesmo autor. No entanto, dado o grande número de autores que publicam sobre a temática, ela também parece ser tópico potencial para futuros estudos e publicações. 


\section{Conclusões}

O objetivo deste trabalho foi analisar, por meio da bibliometria, a produção científica quanto ao tema certificação do café, apontando abordagens crescentes e potenciais e também as lacunas de pesquisa existentes na literatura. Na primeira análise realizada nas 16.655 publicações sobre café, a certificação se mostrou um tema ainda pouco abordado nas pesquisas sobre café, visto que a palavra "certification" apareceu apenas 13 vezes nos títulos, resumos e palavras-chave dos estudos. As temáticas que prevalecem, conforme o mapa de palavras, são as que relacionam o consumo de café à saúde e os aspectos químicos da bebida. Já nas 791 publicações sobre certificação do café, a maior parte dos estudos é da área do Meio Ambiente e Agronomia, como enfoque na certificação fairtrade. A área econômica é responsável por $18 \%$ das publicações sobre certificação de café. Contudo, os estudos sobre o tema mais do que triplicaram ao longo do período analisado.

A partir dos resultados apresentados, algumas lacunas de pesquisa foram observadas e propõe-se uma agenda científica sobre o tema. Apesar de haver estudos econômicos sobre certificação de café, observou-se a ausência de publicações sobre os preços e prêmios por qualidade - certificação, por exemplo. As palavras "preço" e "prêmio" não foram encontradas em nenhum dos clusters identificados. Assim, entre as possibilidades para estudos futuros, sinaliza-se a necessidade de mais estudos sobre os efeitos monetários da certificação do café para os produtores, principalmente pelo fato da motivação econômica ter sido identificada por lbnu et al. (2015) como a principal motivação dos agricultores para a certificação de cafés. Portanto, embora o debate econômico pareça permear diferentes áreas de pesquisa, a literatura científica sobre o tópico possui poucos estudos que investigam o impacto econômico das certificações de café para produtores e/ou consumidores.

Do mesmo modo, as palavras "lucro", "lucratividade" e "competitividade" também não foram encontradas nos estudos, indicando que esses aspectos econômicos também receberam pouca atenção até agora. $O$ fato chama a atenção para necessidade de mais estudos que incluam na avaliação de impacto das certificações a mensuração do lucro e a competitividade dos produtores certificados. Sugerem-se pesquisas que incluam estudos de caso com produtores certificados e também a comparação com produtores não certificados com semelhanças entre si.

Brasil, México, Nicarágua e Costa Rica aparecem entre os países mais pesquisados, porém apenas o Brasil figura entre os que mais publicam sobre certificação. Sendo assim, outros autores e instituições latino-americanas poderiam voltar suas pesquisas à temática, já que esses países, pouco encontrados nos resultados, têm vários produtores de café que podem se beneficiar das certificações.

Sabe-se que os resultados aqui apresentados não representam toda a produção científica mundial sobre o tema pesquisado, dada a seleção de uma única base de dados e o período analisado. Ainda que número de publicações tenha sido elevado e tenha se considerado a mais importante base de dados de períodicos mundial, elas representam apenas uma fração da produção científica global. Apesar das limitações, este trabalho contribui na identificação de abordagens crescentes e potenciais e também das lacunas de pesquisa existentes na literatura. Desse modo, ele é pertinente para o período analisado, mas as avaliações devem ser constantes e periódicas, visto que as bases de dados se atualizam diariamente. Como recomendação para estudos futuros, sugere-se a expansão das bases de dados, o 
estudo dos tipos de certificação separadamente e também a combinação com outros estudos qualitativos na análise das publicações.

\section{Referências}

BALLESTERO, I. G., ZIMMERMANN, S. M. V., DIAS, G. M., \& PARO, C. E. Um Cafezinho e a Conta: a Certificação do Café Orgânico no Brasil. Revista Metropolitana de Sustentabilidade, v.9, n.2, p.67-85, 2019.

BARROS, F.; PINSKY, V.; NASCIMENTO, F.; FISCHMANN, A. Fair trade: international literature review and research agenda. Latin American Journal of Management for Sustainable Development, v. 2, n. 3-4, p. 315-331, 2015.

BART, M.; TAMRU, S.; KUMA, T.; NYARKO, Y. Structure and Performance of Ethiopia's Coffee Export Sector. International Agricultural Trade Research Consortium's (IATRC's) Annual Meeting: Food, Resources and Conflict, San Diego, CA., 2014.

CALDARELLI, C. E.; GILIO, L.; ZILBERMAN, D. The Coffee Market in Brazil: challenges and policy guidelines. Revista de Economia, v. 39, n. 69, 2019.

CHIPUTWA, B.; QAIM, M.; SPIELMAN, D. J. Food Standards, Certification, and Poverty among Coffee Farmers in Uganda. World Development, v. 66, p. 400-412, 2015.

CLARIVATE ANALYTICS. Disponível em: https://clarivate.com/products/web-ofscience/databases/. Acesso em: 01 de maio de 2019.

COMPANHIA NACIONAL DE ABASTECIMENTO - CONAB. Café: acompanhamento da safra brasileira. Safra 2019, v. 6, n.1, 2019. Disponível em: https://www.conab.gov.br/info-agro/safras/cafe. Acesso em: 15 de abril de 2019.

CONSELHO NACIONAL DO CAFÉ. Adido do USDA estima safra 2018/19 de café do Equador em 255 mil sacas. 2018. Disponível em: http://www.cncafe.com.br/site/interna.php?id=14102. Acesso em: 01 de maio de 2019.

CONSÓRCIO PESQUISA CAFÉ. África produz mais de $10 \%$ da safra mundial de café. $2019 . \quad$ Disponível em: http://www.consorciopesquisacafe.com.br/index.php/imprensa/noticias/923-2019-0405-17-51-56. Acesso em: 16 de abril de 2019.

DA SILVA, C. J. R. S.; BENJAMIM, C. J. R.; CARVALHO, L. B.; ROCHA, E. M. B.; MORI, E. (2018). Determinação do teor de cafeína em diferentes tipos de cafés. DEMETRA: Alimentação, Nutrição \& Saúde, v.13, n.2, p. 477-484, 2018.

DE MARIA, Y. Y.; GOMIDE, L. M. M. Cafeína e café: a dualidade entre seus efeitos tóxicos e antioxidantes. Revista InterSaúde, v. 1, n. 1, p. 73-85, 2019.

EMBRAPA. Árvore do Conhecimento da agricultura familiar do Território do Sisal. 2004. Disponível em: https://www.agencia.cnptia.embrapa.br/gestor/territorio_sisal/arvore/CONT000fckmh ced02wx5eo0a2ndxyol4f5z3.html. Acesso em: 11 de maio de 2019. 
EMBRAPA. Vietnã e Indonésia produzem $25 \%$ do café no mundo. 2016. Disponível em: $\quad$ https://www.embrapa.br/busca-de-noticias/-/noticia/17340728/vietna-eindonesia-produzem-25-do-cafe-no-mundo. Acesso em: 11 de maio de 2019.

EMBRAPA. Consumo dos cafés especiais cresce $12 \%$ ao ano em nível mundial. 2018. Disponível em: https:/www.embrapa.br/busca-de-noticias//noticia/36260834/consumo-dos-cafes-especiais-cresce-12-ao-ano-em-nivel-mundial. Acesso em: 11 de maio de 2019.

FISCHER, E.; QAIM, M. Smallholder Farmers and Collective Action: What Determines the Intensity of Participation? Journal of Agricultural Economics, v.65, p.683-702, 2014.

HAGGAR, J.; SOTO, G.; CASANOVES, F.; VIRGINIO, E. M. Environmental-economic benefits and trade-offs on sustainably certified coffee farms. Ecological Indicators, v.79, p.330-337, 2017.

IBNU, M.; GLASBERGEN, P.; OFFERMANS, A.; ARIFIN, B. Farmer Preferences for Coffee Certification: A Conjoint Analysis of the Indonesian Smallholders. Journal of Agricultural Science, v.7, n.6, p. 20-35, 2015.

INTERNATIONAL COFFEE ORGANIZATION. World coffee consumption 2019. Disponível em: http://www.ico.org/prices/new-consumption-table.pdf. Acesso em: 20 de abril de 2019.

KILLEEN, T.; HARPER, G. Coffee in the 21st century. Will climate change and increased demand lead to new deforestation? Research Paper. Conservation International, 2016.

LOUREIRO, M. L.; LOTADE, J. Do fair trade and eco-labels in coffee wake up the consumer conscience? Ecological Economics, v.53, n.1, p.129- 138, 2005.

MARTINI, D.; DEL BO', C.; TASSOTTI, M.; RISO, P.; DEL RIO, D.; BRIGHENTI, F.; PORRINI, M. Coffee Consumption and Oxidative Stress: A Review of Human Intervention Studies. Molecules, v.21, n.979, 2016.

MELO, M. F. S.; SOUZA, R. C.; CAMPOS-SILVA, W. L.; AMATO-NETO, J. Certificação Sustentável para café: Revisão sistemática da literatura e lacunas de pesquisa. Revista Espacios, v.38, n.17, p.31-45, 2017.

OYA, C.; SCHAEFER, F.; SKALIDOU, D.; MCCOSKER, C.; LANGER, L. Effects of certification schemes for agricultural production on socio-economic outcomes in lowand middle-income countries: a systematic review. Campbell Systematic Review, v.13, n.1; p.1-346, 2017.

PELSMACKER, P.; DRIESEN, L.; RAYP, G. Do consumers care about ethics? Willingness to pay for fair-trade coffee. Journal of Consumer Affairs, v.39, n.2, p.363-385, 2005.

PYK, F.; HATAB, A. A. Fairtrade and Sustainability: Motivations for Fairtrade Certification among Smallholder Coffee Growers in Tanzania. Sustainability, v.10, n.5, p.1551, 2018. 
PODHORSKY, A. A positive analysis of fairtrade certification. Journal of Development Economics, v. 116, p. 169-185, 2015.

RAMALHO, M. E. O.; SOARES, N. M. Café e seus benefícios. Revista Interface Tecnológica, v. 15, n. 1, p. 285-292, 2018.

ROHDE, L. A.; CASTAGNA, A. C. Os diferentes clusters de consumidores do café brasileiro: estudo sobre as atitudes, crenças e marca Brasil. Revista Estudo \& Debate, v. 23, n. 2, 2016.

RUGGERI, G.; ORSI, L.; CORSI, S. A bibliometric analysis of the scientific literature on Fairtrade labeling. International Journal of Consumer Studies, v.43, n.2, p.134152, 2019.

SAMPER, L.; GIOVANNUCCI, D.; VIEIRA, L. M. The powerful role of intangibles in the coffee value chain. Economic research paper no.39. Geneva: WIPO, 2017.

SINDICATO DA INDÚSTRIA DE CAFÉ DO ESTADO DE MINAS GERAIS. Café no mundo. $2005 . \quad$ Disponível em: http://sindicafemg.com.br/plus/modulos/conteudo/?tac=importancia-da-cafeicultura.

Acesso em: 19 de maio de 2019.

SPECIALTY COFFEE ASSOCIATION OF AMERICA - SCAA. SCAA protocols: Cupping Specialty Coffee. 2015.2 Disponível em: http://www.scaa.org/?page=resources\&d=cupping-protocols. Acesso em: 09 de abril de 2019.

TOLESSA, K; RADEMAKER, M.; DE BAETS, B.; BOECKX, P. Prediction of specialty coffee cup quality based on near infrared spectra of green coffee beans. Talanta, v.150, p.367-374, 2016.

UN COMTRADE DATABASE. 2018.2 Disponível em: https://comtrade.un.org/db/mr/rfCommoditiesList.aspx?px=H2\&cc=090111. Acesso em: 13 de março de 2019.

VAN ECK, N. J.; WALTMAN, L. Software survey: VOSviewer, a computer program for bibliometric mapping. Scientometrics, v.84, n.2, p.523-538, 2010.

VAN ECK, N. J.; WALTMAN, L. Citation-based clustering of publi-cations using CitNetExplorer and VOSviewer. Scientometrics, v.111, n.2, p.1053-1070, 2017.

VOSVIEWER. Visualizing scientific landscapes. Version 1.6.10. 2019. Disponível em: http://www.vosviewer.com/. Acesso em: 13 de março de 2019.

WORLD COFFEE RESEARCH. Annual report 2017. Creating the future of coffee. WCR, 2017.

WORLD INTELLECTUAL PROPERTY ORGANIZATION. World Intellectual Property Report: Intangible Capital in Global Value Chains. 2017. 